\title{
Structure and Electronic Properties of Alkylthiophenes Coupled by Head-to-Tail and Head-to-Head Regioselectivity ${ }^{\dagger}$
}

\author{
Marcos A. de Oliveira*,a, Wagner B. de Almeida ${ }^{b}$ and Hélio F. dos Santos ${ }^{b}$ \\ ${ }^{a}$ Departamento de Química, Instituto de Ciências Exatas, Universidade Federal de Juiz de Fora, Campus Universitário \\ Martelos, 36036-330 Juiz de Fora - MG, Brazil \\ ${ }^{b}$ Departamento de Química, Instituto de Ciências Exatas, Universidade Federal de Minas Gerais, Campus Pampulha, \\ 31270-901Belo Horizonte - MG, Brazil
}

\begin{abstract}
No presente artigo, métodos teóricos foram utilizados na análise da estrutura e propriedades eletrônicas de oligômeros de alquiltiofenos considerando diferentes regiosseletividades. A lacuna de energia entre as bandas de valência e condução foi calculada nos níveis ab initio Hartree-Fock (HF) e teoria do funcional de densidade (DFT) e semi-empírico ZINDO/S-CI. Os resultados mostraram que o isômero Head-Head-Tail-Tail (HH-TT) apresenta menores valores para a lacuna de energia quando oligômeros com mais de três unidades monoméricas são considerados e que a substituição do anel tiofeno por grupos alquila não afeta significativamente a lacuna de energia. Esse resultado é importante no sentido que mostra que polímeros mais processáveis podem ser obtidos através da alquilação sem perda considerável de suas características condutoras.
\end{abstract}

In the present paper a theoretical analysis of alkylthiophenes with Head-Tail-Head-Tail (HT-HT) and Head-Head-Tail-Tail (HH-TT) regioselectivities up to 6 monomeric units was carried out. Structure and electronic properties for the syn and anti forms were calculated by ab initio HartreeFock (HF) and Density Functional Theory (DFT) approaches. The energy gap between the conduction and valence bands was obtained at HF and DFT levels and also calculated with the semiempirical ZINDO/S-CI method. The results showed that the isomer with HH-TT regioselectivity presents lower energy gap for longer oligomers and the substitution of thiophene by alkyl groups does not change significantly the energy gap. This is important in the sense that more processable polymers can be obtained through alkylation without decrease the energy gap that is a molecular properties related to the electronic conductivity. Regarding to the conformational equilibrium, the syn form was found to be stable only for the HT-HT isomer and in this case the energy gap was found to be lower than those calculated for the anti form.

Keywords: alkylthiophenes, HT-TT regioselectivity, HH-TT regioselectivity, polymer alkylation.

\section{Introduction}

Conjugated organic polymers have been subject of intense experimental and theoretical researches since 1977 when this class of materials was fully tested. ${ }^{1}$ Several systems as poly(pyrrol), poly(aniline), poly(phenylthiophene) and poly(alkylthiophene) were prepared and their electronic and optical properties analyzed. ${ }^{2}$ Doped organic molecules were also widely tested for building electronic and photonic devices. ${ }^{3}$

* e-mail: oliveira@ netuno.qui.ufmg.br

'Dedicated to the memory of Professor Jean-Michel Pernaut, who made a great contribution to the development of this research area in our institution.
The substituted $\alpha, \alpha^{\prime}$-oligothiophenes have been considered adequate prototypes for intrinsic electro-active polythiophenes. Their structural and electronic properties can be modulated by group substitution. The polythiophenes are easily oxidized $\pi$-electron systems exhibiting conductivities of $\sim 20{\mathrm{~S} . \mathrm{cm}^{-1}}^{-1}$ and are stable at oxygen atmosphere. ${ }^{3}$ The small oligothiophenes are usually not processable using common solvents, and one way to contour this obstacle is to substitute appropriated molecular positions by alkyl groups, that leads to processable (fusible and soluble) derivatives without losing conductivity.

Some difficulties on the structural understanding of poly(alkylthiophenes) have been pointed out. Images of poly(3-alkylthiophenes) obtained from high resolution 
scanning tunneling microscopy (STM) and atomic force microscopy (AFM) did not present molecular resolution. ${ }^{4}$ The wide angle X-ray technique was used and a lamellar interchain arrange determined. ${ }^{5,6}$ However, despite the experimental data obtained so far, information at molecular level enough for a comprehensive conclusion about organic semiconductors are still necessary.

For the alkylthiophenes the regiochemistry control is an important factor to be considered, once that the coupling type is responsible for different structure and electronic properties. The regioselectivities can be of several types, being the Head-Tail-Head-Tail (HT-HT) and the HeadHead-Tail-Tail (HH-TT) more important (Figure 1). Synthesis of alkylthiophenes yielded $98-100 \%$ of HT-HT coupling. ${ }^{7}$ The regiochemistry analysis was performed from a series of two-dimensional ${ }^{1} \mathrm{H}$ and ${ }^{13} \mathrm{C}$ NMR spectroscopy. ${ }^{8}$ These studies showed that it is possible to prepare regular polymers and that the regioselectivity type governs the conductivity on doped alkylthiophenes. In condensed phase the inter-chain interactions (hopping) and counterion presence modify the polymer structure, increasing the energy gap and consequently reducing the macroscopic conductivity of polymers with HH-TT coupling. ${ }^{8}$

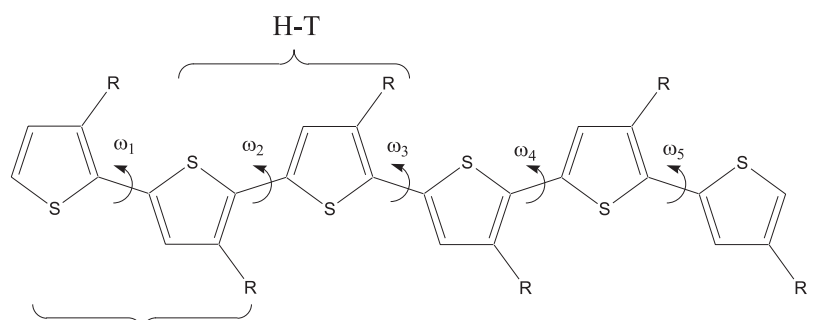

$\mathrm{H}-\mathrm{T}$

(a)

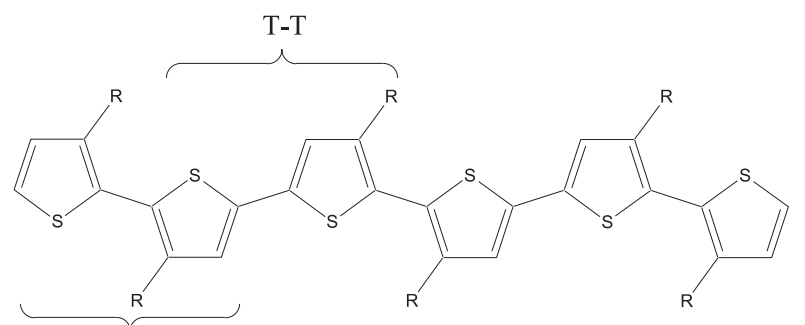

$\mathrm{H}-\mathrm{H}$

(b)

Figure 1. Representation of the structure of alkylthiophene coupled by Head-Tail-Head-Tail (HT-HT) (a) and Head-Head-Tail-Tail (HHTT) (b). The dihedral angle $\omega_{\mathrm{i}}$ is defined considering the sulfur atoms.

The energy gap $\left(\mathrm{E}_{\mathrm{g}}\right)$, determined from bulk polymeric properties, is an important property correlated to the electronic conductivity. Experimentally the $\mathrm{E}_{\mathrm{g}}$ can be obtained from UV spectroscopy through the intersection point between the absorption and emission bands. In this case it is actually the molecular $\mathrm{E}_{0}^{0}$. For the alkylthiophenes the energy gap was measured from cyclic voltammetry (CV) technique as the difference between the oxidation and reduction potentials. Neglecting solvation effects the values obtained from CV technique and UV-VIS spectroscopy could present similar magnitudes.

Recently we have applied theoretical quantum mechanical methods to study thiophene derivatives. ${ }^{9-11}$ Oligomers up to 6 thiophene units have been considered, substituted by groups like $\mathrm{OCH}_{3}, \mathrm{NO}_{2},{ }^{9} \mathrm{CN}^{10}$ and phenyl. ${ }^{11}$ In our previous papers, the energy gap was estimated from LUMO-HOMO energy difference and using the configuration interaction (CI) approach. In the present paper the alkylthiophenes up to 6 monomeric units were studied using quantum mechanical Hartree-Fock (HF) and Density Functional Theory (DFT) methods. Structure and electronic properties are discussed as function of the regiochemistry and size of the oligomers considering the syn and anti conformers.

\section{Methodology}

The syn and anti conformers were found to be stable for the bithiophene parent compound, ${ }^{12}$ so these were the structures considered for substitution by alkyl groups at HT-HT and HH-TT coupling according to the representation in Figure 1. Oligomers up to 6 monomeric units were studied. The geometries for the HT-HT and HHTT couplings were fully optimized at Hartree-Fock (HF) level with the $6-31 \mathrm{G}$ and $6-31 \mathrm{G}(\mathrm{d})$ basis sets. ${ }^{13}$ The electronic properties were calculated at the Density Functional Theory (DFT) level ${ }^{14}$ with the local functional (SVWN) $)^{14-16}$ using the HF optimized geometries. The basisset employed was the $6-31 \mathrm{G}(\mathrm{d})$ in the single point calculations. The molecular energy gap $\left(\mathrm{E}_{0}^{0}\right)$, between ground and excited states, was calculated as the LUMOHOMO energy difference and also with the aid of the configuration interaction (CI) approach as implemented in the semiempirical method ZINDO/S-CI developed by Zerner and co-workers, using the ARGUSLAB program. ${ }^{17}$ The latter was recently used to predict band gaps in neutral heterocyclic conjugated polymers showing very good agreement with experimental data. ${ }^{18}$ It is important to make clear here that the estimated energy gap from the frontiers molecular orbitals is supported by the Koopmans' theorem based on HF method, ${ }^{19}$ including semiempirical approaches, and DFT methods. ${ }^{20}$ At DFT level the intrinsic value to $\mathrm{E}_{0}^{0}$ can be estimated directly from the eigenvalues of the Kohn-Sham equations, however the accuracy of the predicted properties strongly depends on the approximate exchange-correlation functional. ${ }^{21}$ 


\section{Results and Discussion}

In the first part of this article we analyze the effect of the alkyl substitution on the structure and electronic properties of syn and anti bithiophene molecules. Tables 1 and 2 report the inter-rings dihedral angle $(\omega)$ and energy gap $\left(\mathrm{E}_{0}^{0}\right)$ calculated for the bithiophene (2T) and alkylbithiophene derivatives with HT (Table 1) and HH (Table 2) regioselectivities. For the parent compound 2T, the inter-ring dihedral angle calculated for the anti form from the HF/6-31G(d) geometry $\left(\omega=147^{\circ}\right)$ was found to be in good agreement with those obtained from higher levels of theory ${ }^{12}$ and experimental data. ${ }^{22}$ Calculations involving substituted HT alkylbithiophenes provided values for $\mathrm{w}$ ranging from 119 (propyl, 2T-C3) to $108^{\circ}$ (octadecyl, 2TC18) for anti conformers and from 71 (propyl, 2T-C3) to $60^{\circ}$ (octadecyl, 2T-C18) for syn forms (Table 1). For the ant $i \mathrm{HH}$ molecules, the inter-ring dihedral angle was found to be close to $95^{\circ}$ (see Table 2). As already discussed in the paper of Bongini and Bottoni, ${ }^{23}$ the $\mathrm{HF}$ result for $\mathrm{HH}$ isomer leads to only one minimum on the potential energy surface (PES) with $\omega$ close to $90^{\circ}$. A syn form $\left(\omega=60^{\circ}\right)$ was obtained at MP2 level and a syn and anti equilibrium was found only at DFT level of theory. ${ }^{23}$ For the HT alkylderivatives we obtained both forms in equilibrium even at HF level (see Table 1), with the syn form found to be slightly more stable $(0.32 \mathrm{kcal} / \mathrm{mol}$ for $2 \mathrm{~T}-\mathrm{C} 6)$. Others theoretical studies dealing with conformational analysis of alkylbithiophenes have also been reported using semiempirical methods. ${ }^{24}$

The structural distortion is reflected on the energy gap. For the $2 \mathrm{~T}$ in the anti conformation, the experimental $\mathrm{E}_{0}^{0}$ is $3.68 \mathrm{eV}^{25}$ that is in good agreement with the theoretical values calculated for the anti form at SVWN/6-31G(d)// $\mathrm{HF} / 6-31 \mathrm{G}(\mathrm{d})(3.43 \mathrm{eV})$ and ZINDO/S-CI/HF/6-31G(d) $(3.71 \mathrm{eV})$ levels of theory. For the anti HT alkylbithiophenes the calculated $\mathrm{E}_{0}^{0}$ values at $\mathrm{SVWN} / 6$ $31 \mathrm{G}(\mathrm{d}) / / \mathrm{HF} / 6-31 \mathrm{G}(\mathrm{d})$ level were found to be $4.05 \mathrm{eV}$ for alkyl side chain longer than propyl, being higher than the value calculated for the syn conformation, which was 3.86 $\mathrm{eV}$ (see Table 1). The corresponding values for anti $\mathrm{HH}$ isomers were constant and equal to $4.35 \mathrm{eV}$ (Table 2). An increase of the energy gap is observed from $2 \mathrm{~T}$ to $2 \mathrm{~T}-\mathrm{C} 3$ alkybithiophenes associated to the distortion of the geometry. However, the substitution of the $2 \mathrm{~T}$ molecule by longer alkyl groups does not lead to a significant variation of the $\mathrm{E}_{0}^{0}$. For the HT structure, the energy gap

Table 1. Inter-ring torsional angle ( $\omega$ in degrees) and energy gap $\left(\mathrm{E}_{0}^{0}\right.$ in $\mathrm{eV}$ ) calculated for the syn and anti (in brackets) alkylbithiophenes with HT regioselectivity

\begin{tabular}{|c|c|c|c|c|c|c|}
\hline & \multicolumn{2}{|c|}{$\mathrm{HF}^{\mathrm{b}}$} & \multirow{2}{*}{$\begin{array}{c}\mathrm{SVWN} / / \mathrm{HF}^{\mathrm{b}} \\
\mathrm{E}_{0}^{0}\end{array}$} & \multicolumn{2}{|c|}{ ZINDO/S-CI//HF ${ }^{c}$} & \multirow{2}{*}{$\begin{array}{l}\text { Exp. }{ }^{\mathrm{d}} \\
\mathrm{E}_{0}^{0}\end{array}$} \\
\hline & $\omega$ & $\mathrm{E}_{0}^{0}$ & & $\mathrm{E}_{0}^{0}(10 \%)$ & $\mathrm{E}_{0}^{0}(100 \%)$ & \\
\hline $2 \mathrm{~T}$ & $45[147]$ & $10.80[10.52]$ & $3.60[3.43]$ & $4.27[4.14]$ & $3.83[3.71]$ & 3.68 \\
\hline $2 \mathrm{~T}-\mathrm{C} 3$ & $71[119]$ & $11.59[11.22]$ & $4.06[3.85]$ & $4.62[4.43]$ & $4.15[3.99]$ & - \\
\hline 2T-C6 & $60[108]$ & $11.24[11.58]$ & $3.86[4.05]$ & $4.41[4.59]$ & $3.99[4.15]$ & - \\
\hline $2 \mathrm{~T}-\mathrm{C} 8$ & $60[108]$ & $11.24[11.58]$ & $3.86[4.05]$ & $4.41[4.59]$ & $3.99[4.15]$ & - \\
\hline $2 \mathrm{~T}-\mathrm{C} 12$ & $60[108]$ & $11.24[11.58]$ & $3.86[4.05]$ & $4.41[4.59]$ & (e) & - \\
\hline 2T-C18 & $60[108]$ & $11.24[11.58]$ & $3.86[4.05]$ & $4.41[4.59]$ & (e) & - \\
\hline
\end{tabular}

${ }^{a}$ The labels C3, C6, C8, C12 and C18 stand for propyl, hexyl, octyl, dodecyl and octadodecyl respectively; ${ }^{\text {b}}$ The basis-set used were 6-31G(d) for geometry optimization and energy calculation; 'The values in parenthesis correspond to the active space used in the CI procedure; ${ }^{\mathrm{d}}$ Experimental energy gap $(\mathrm{eV})$ determined from UV-VIS spectroscopy for the anti form of the bithiophene molecule, see reference; ${ }^{25} \mathrm{e} F o r$ these molecules it was not possible to perform a CI considering all valence molecular orbitals, due to the size of the systems.

Table 2. Inter-ring torsional angle ( $\omega$ in degrees) and energy gap $\left(\mathrm{E}_{0}^{0} \mathrm{in} \mathrm{eV}\right)$ calculated for the anti alkylbithiophenes with $\mathrm{HH}$ regioselectivity

\begin{tabular}{|c|c|c|c|c|c|c|}
\hline & \multicolumn{2}{|c|}{$\mathrm{HF}^{\mathrm{b}}$} & \multirow{2}{*}{$\begin{array}{c}\mathrm{SVWN} / / \mathrm{HF}^{\mathrm{b}} \\
\mathrm{E}_{0}^{0} \\
\end{array}$} & \multicolumn{2}{|c|}{$\mathrm{ZINDO} / \mathrm{S}-\mathrm{CI} / / \mathrm{HF}^{\mathrm{c}}$} & \multirow{2}{*}{$\begin{array}{c}\text { Exp. }^{\mathrm{d}} \\
\mathrm{E}_{0}^{0}\end{array}$} \\
\hline & $\omega$ & $\mathrm{E}_{0}^{0}$ & & $\mathrm{E}_{0}^{0}(10 \%)$ & $\mathrm{E}_{0}^{0}(100 \%)$ & \\
\hline $2 \mathrm{~T}$ & 147 & 10.52 & 3.43 & 4.14 & 3.71 & 3.68 \\
\hline $2 \mathrm{~T}-\mathrm{C} 3$ & 95 & 12.04 & 4.35 & 4.82 & 4.27 & - \\
\hline 2T-C6 & 95 & 12.04 & 4.35 & 4.78 & 4.27 & - \\
\hline $2 \mathrm{~T}-\mathrm{C} 8$ & 95 & 12.04 & 4.35 & 4.78 & 4.27 & - \\
\hline 2T-C12 & 95 & 12.04 & 4.35 & 4.78 & (e) & - \\
\hline 2T-C18 & 95 & 12.04 & 4.35 & 4.78 & (e) & - \\
\hline
\end{tabular}

aThe labels C3, C6, C8, C12 and C18 stand for propyl, hexyl, octyl, dodecyl and octadodecyl respectively; ${ }^{\text {b}}$ The basis-set used was 6-31G(d) for

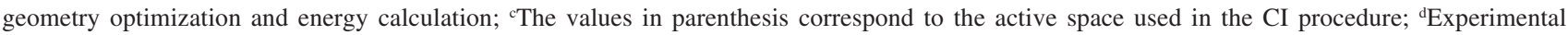
energy gap (eV) determined from UV-VIS spectroscopy for the anti form of the bithiophene molecule, see reference; ${ }^{25}{ }^{\mathrm{F}} \mathrm{For}$ these molecules it was not possible to perform a CI considering all valence molecular orbitals, due to the size of the systems. 
calculated for the syn form was $3.86 \mathrm{eV}$ (SVWN//HF) for alkylbithiophene substituted by side chain longer than propyl, being lower than the value found for the anti form. For the $2 \mathrm{~T}$ and $2 \mathrm{~T}-\mathrm{C} 3$ derivatives, the $\mathrm{E}_{0}^{0}$ calculated for the syn conformation were higher than those obtained for the anti isomer. This can be understood by analyzing the out of plane distortion due to the presence of the alkyl group. In the $2 \mathrm{~T}$ molecule, $\omega=45^{\circ}$ (syn) and $147^{\circ}$ (anti), showing that the anti form is only $33^{\circ}$ out of plane that is in accordance with the lower energy gap. This same qualitative trend was observed for the 2T-C 3 molecule, with the syn form $71^{\circ}\left(\omega=71^{\circ}\right)$ and the anti conformation $61^{\circ}\left(\omega=119^{\circ}\right)$ out of plane. This behavior is reversed for the 2T-C6 where the out of plane distortion is more pronounced in the anti form: $60^{\circ}(\mathrm{syn})$ and $72^{\circ}$ (anti). The same trend on the energy gap was observed at the other levels of theory (see Table 1). At the ZINDO/S-CI//HF/6$31 \mathrm{G}(\mathrm{d})$ level of theory the $\mathrm{E}_{0}^{0}$ values are dependent on the active space used. For the $2 \mathrm{~T}$ parent compound the $\mathrm{E}_{0}^{0}$ was found to be 4.27 (syn) and $4.14 \mathrm{eV}$ (anti) when 10\% of the valence molecular orbitals (VMO) were used and 3.83 (syn) and $3.71 \mathrm{eV}$ (anti) when all the VMO were considered, which is closer to the experimental value $(3.68 \mathrm{eV})$. This result shows the necessity to use expanded active space to reproduce energy gaps for bithiophene like molecules within the ZINDO/S-CI approach. Similar results have been recently obtained for cyanothiophenes derivatives. ${ }^{10}$

The results reported here are important in the sense that alkyl derivatives can improve the polymer processability without significant lowering of the conductivity, if we consider only the band gap molecular parameter. In the next part of the present study we analyzed the structure and electronic properties of oligo(hexylthiophene) up to 6 monomeric units substituted at HT-HT and HH-TT positions (Tables 3-6). In the Table 3 the inter-rings dihedral angles $\left(\omega_{\mathrm{i}}\right)$ of the oligo(hexylthiophene) derivatives with 2 (2T-C6) up 6 (6T-C6) monomeric units are reported for the
HT-HT regioselectivity. The structures were fully optimized at $\mathrm{HF} / 6-31 \mathrm{G}$ and $\mathrm{HF} / 6-31 \mathrm{G}(\mathrm{d})$ levels of theory considering the syn and anti conformations. These structures were constructed considering the local conformation as being either all syn or all trans (see Figure 2). The torsional PES for such large system is quite complicate with many distinct local minima and combination of syn and anti forms over the chain can certainly leads to more stable structures. In the present work we analyze only the most stable all trans and less stable all syn forms (Figure 2). For the 5T-C6 derivate the anti conformation was found to be only $0.1 \mathrm{kcal} / \mathrm{mol}$ more stable than the syn one at HF/6-31G* level of theory. The results show that the anti structure is more sensitive to the basis-set, with the geometry found to be less planar at the HF/6-31G(d) level. The inter-rings dihedral angles calculated for the HH-TT isomer is given in Table 4 for the anti form (Figure 2b). Analyzing the values in Table 4 it can be noted two distinct sets of dihedral angles relative to the
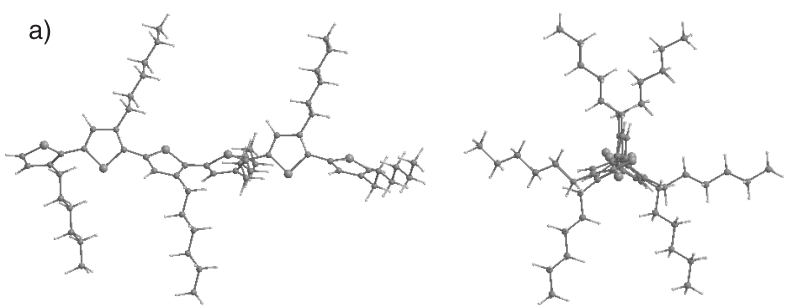

b)
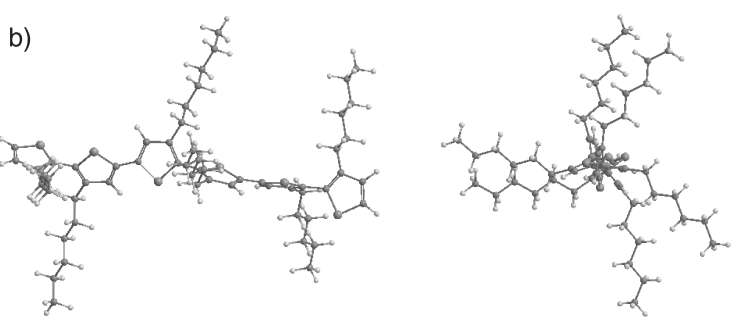

Figure 2. HF/6-31G optimized geometries of the anti conformation of oligo(hexyltiophene) with six monomeric units at HT-HT (a) and HH-TT (b) regioselectivity.

Table 3. Inter-ring torsional angles ( $\omega_{\mathrm{i}}$ in degrees) calculated for the oligohexylthiophenes with HT-HT regioselectivity presenting syn and anti conformers. The geometries were optimized at HF/6-31G and HF/6-31G(d) (values in brackets)

\begin{tabular}{|c|c|c|c|c|c|c|c|c|c|c|}
\hline & \multicolumn{5}{|c|}{ anti } & \multicolumn{5}{|c|}{ syn } \\
\hline & $\omega_{1}$ & $\omega_{2}$ & $\omega_{3}$ & $\omega_{4}$ & $\omega_{5}$ & $\omega_{1}$ & $\omega_{2}$ & $\omega_{3}$ & $\omega_{4}$ & $\omega_{5}$ \\
\hline 2T-C6 & $\begin{array}{c}112 \\
{[108]}\end{array}$ & & & & & $\begin{array}{c}60 \\
{[60]}\end{array}$ & & & & \\
\hline 3T-C6 & $\begin{array}{c}114 \\
{[110]}\end{array}$ & $\begin{array}{c}113 \\
{[109]}\end{array}$ & & & & $\begin{array}{c}57 \\
{[59]}\end{array}$ & $\begin{array}{c}58 \\
{[60]}\end{array}$ & & & \\
\hline $4 \mathrm{~T}-\mathrm{C} 6$ & $\begin{array}{c}114 \\
{[110]}\end{array}$ & $\begin{array}{c}115 \\
{[111]}\end{array}$ & $\begin{array}{c}112 \\
{[109]}\end{array}$ & & & $\begin{array}{c}58 \\
{[59]}\end{array}$ & $\begin{array}{c}58 \\
{[59]}\end{array}$ & $\begin{array}{c}59 \\
{[59]}\end{array}$ & & \\
\hline 5T-C6 & $\begin{array}{c}112 \\
{[109]}\end{array}$ & $\begin{array}{c}115 \\
{[111]}\end{array}$ & $\begin{array}{c}115 \\
{[111]}\end{array}$ & $\begin{array}{c}126 \\
{[120]}\end{array}$ & & $\begin{array}{c}59 \\
{[59]}\end{array}$ & $\begin{array}{c}59 \\
{[60]}\end{array}$ & $\begin{array}{c}57 \\
{[59]}\end{array}$ & $\begin{array}{c}55 \\
{[57]}\end{array}$ & \\
\hline 6T-C6 & $\begin{array}{c}112 \\
{[109]}\end{array}$ & $\begin{array}{c}115 \\
{[111]}\end{array}$ & $\begin{array}{c}115 \\
{[111]}\end{array}$ & $\begin{array}{c}127 \\
{[121]}\end{array}$ & $\begin{array}{c}127 \\
{[120]}\end{array}$ & $\begin{array}{c}58 \\
{[59]}\end{array}$ & $\begin{array}{c}59 \\
{[60]}\end{array}$ & $\begin{array}{c}58 \\
{[59]}\end{array}$ & $\begin{array}{c}53 \\
{[56]}\end{array}$ & $\begin{array}{c}69 \\
{[67]}\end{array}$ \\
\hline
\end{tabular}


Table 4. Inter-ring torsional angles ( $\omega_{\mathrm{i}}$ in degrees) calculated for the oligohexylthiophenes with HH-TT regioselectivity in the anti form. The geometries were optimized at HF/6-31G and HF/6-31G(d) (values in brackets)

\begin{tabular}{cccccc}
\hline & \multicolumn{5}{c}{ HH-TT } \\
& $\omega_{1}$ & $\omega_{2}$ & $\omega_{3}$ & $\omega_{4}$ & $\omega_{5}$ \\
\hline 2T-C6 & 97 & & & & \\
& {$[95]$} & & & & \\
3T-C6 & 96 & 170 & & & \\
& {$[96]$} & {$[151]$} & & & \\
4T-C6 & 96 & 169 & 96 & & \\
& {$[96]$} & {$[150]$} & {$[96]$} & & \\
5T-C6 & 96 & 177 & 96 & 174 & \\
& {$[96]$} & {$[151]$} & {$[96]$} & {$[150]$} & \\
6T-C6 & 96 & 169 & 96 & 169 & 96 \\
& {$[96]$} & {$[150]$} & {$[96]$} & {$[150]$} & {$[96]$} \\
\hline
\end{tabular}

$\mathrm{HH}\left(\omega \sim 95^{\circ}\right)$ and TT $\left(\omega \sim 170^{\circ}\right)$ moieties (see Figure $1 \mathrm{~b}$ and $2 b)$. For the latter the effect of polarization functions is more pronounced, given a less planar geometry at $\mathrm{HF} / 6-31 \mathrm{G}(\mathrm{d})$ $\left(\omega \sim 150^{\circ}\right.$ in the TT moiety).
The HT-HT and HH-TT calculated energy gaps values are reported in Tables 5 and 6 . In a general way the $\mathrm{E}_{0}^{0}$ is slightly smaller for the oligomers in the HH-TT regioselectivity, except for the 2T-C6 where it was found a lower value of $\mathrm{E}_{0}^{0}$ for HT-HT. This result is contrary to experimental data for polymers in condensate phase where a lower energy gap is predicted for the HT-HT regioselectivity. ${ }^{8}$ This disagreement might be regarded to the intermolecular interactions. It is interesting to note the decreasing in the energy gap, as the oligomer chain becomes larger. For the anti conformations with HT-HT regioselectivity the predicted values changed from 4.05 to $3.40 \mathrm{eV}$ at the SVWN/6-31G(d)//HF/6-31G(d) level and from 3.77 to $2.99 \mathrm{eV}$ at the SVWN/6-31G(d)//HF/6-31G. For the HH-TT regioselectivity the $\mathrm{E}_{0}^{0}$ values changed from 4.35 to $3.20 \mathrm{eV}$ at the SVWN/6-31G(d)//HF/6-31G(d) level and from 4.12 to $2.79 \mathrm{eV}$ at the SVWN/6-31G(d)//HF/6$31 \mathrm{G}$. For the anti form of the HH-TT isomer the $\mathrm{E}_{0}^{0}$ calculated for the 6T-C6 was found to be slightly higher than the

Table 5. Energy gap $\left(\mathrm{E}_{0}^{0} \mathrm{in} \mathrm{eV}\right)$ calculated for the oligo(hexylthiophenes) up to 6 monomeric units at the SVWN/6-31G(d) level of theory. The values obtained considering the HF/6-31G and HF/6-31G(d) (values in brackets) optimized geometries are reported

\begin{tabular}{|c|c|c|c|c|}
\hline & \multicolumn{2}{|c|}{$\begin{array}{c}\mathrm{SVWN} / 6-31 \mathrm{G}(\mathrm{d}) / / \mathrm{HF} / 6-31 \mathrm{G} \\
{[\mathrm{SVWN} / 6-31 \mathrm{G}(\mathrm{d}) / / \mathrm{HF} / 6-31 \mathrm{G}(\mathrm{d})]}\end{array}$} & \multirow{3}{*}{$\begin{array}{c}\begin{array}{c}\text { SVWN/6-31G(d)//HF/6-31G } \\
{[\mathrm{SVWN} / 6-31 \mathrm{G}(\mathrm{d}) / / \mathrm{HF} / 6-31 \mathrm{G}(\mathrm{d})]}\end{array} \\
\text { HT-HT } \\
s y n\end{array}$} & \multirow[t]{3}{*}{ Exp. ${ }^{a}$} \\
\hline & HT-HT & HH-TT & & \\
\hline & & & & \\
\hline $2 \mathrm{~T}-\mathrm{C} 6$ & $3.77[4.05]$ & $4.12[4.35]$ & $3.63[3.86]$ & \\
\hline $3 \mathrm{~T}-\mathrm{C} 6$ & $3.43[3.65]$ & $2.94[3.19]$ & $3.28[3.53]$ & \\
\hline $4 \mathrm{~T}-\mathrm{C} 6$ & $3.30[3.65]$ & $2.86[3.15]$ & $3.16[3.41]$ & \\
\hline $5 \mathrm{~T}-\mathrm{C} 6$ & $3.15[3.53]$ & $2.77[3.05]$ & $2.99[3.25]$ & \\
\hline 6T-C6 & $2.99[3.40]$ & $2.79[3.20]$ & $2.90[3.15]$ & \\
\hline $\mathrm{T}-\mathrm{C} 6^{\mathrm{b}}$ & $2.61[3.22]^{\mathrm{c}}$ & $2.60[3.09]^{\mathrm{c}}$ & $2.54[2.79]^{\mathrm{c}}$ & 2.32 \\
\hline
\end{tabular}

${ }^{\mathrm{a} F r o m}$ reference 26 ; ${ }^{\mathrm{b}}$ The energy gap for the infinity polymer was calculated considering a linear behavior of $\mathrm{E}_{0}^{0}$ with $1 / \mathrm{n}$, being $\mathrm{n}$ the number of monomeric units; 'These values were calculated without the 2T-C6 data.

Table 6. Energy gap $\left(\mathrm{E}_{0}^{0}\right.$ in eV) calculated for the oligo(hexylthiophenes) up to 6 monomeric units at ZINDO-S/CI//HF/6-31G(d) level of theory

\begin{tabular}{|c|c|c|c|c|c|c|c|}
\hline & \multicolumn{6}{|c|}{ ZINDO-S/CI//HF/6-31G(d) } & \multirow[t]{4}{*}{ Exp. ${ }^{a}$} \\
\hline & \multicolumn{2}{|c|}{ syn } & \multicolumn{4}{|c|}{ anti } & \\
\hline & \multicolumn{2}{|c|}{ HT-HT } & \multicolumn{2}{|c|}{ HT-HT } & \multicolumn{2}{|c|}{ HH-TT } & \\
\hline & $10 \%$ & $100 \%^{\mathrm{b}}$ & $10 \%$ & $100 \%^{\mathrm{b}}$ & $10 \%$ & $100 \%^{\mathrm{b}}$ & \\
\hline 2T-C6 & 4.41 & 3.99 & 4.59 & 4.15 & 4.78 & 4.27 & \\
\hline $3 \mathrm{~T}-\mathrm{C} 6$ & 4.07 & 3.69 & 4.27 & 3.87 & 3.88 & 3.49 & \\
\hline $4 \mathrm{~T}-\mathrm{C} 6$ & 3.92 & 3.58 & 4.13 & 3.75 & 3.78 & 3.40 & \\
\hline $5 \mathrm{~T}-\mathrm{C} 6$ & 3.80 & 3.48 & 4.00 & 3.63 & 3.66 & 3.30 & \\
\hline $6 \mathrm{~T}-\mathrm{C} 6$ & 3.74 & 3.44 & 3.88 & 3.53 & 3.62 & 3.26 & \\
\hline $\mathrm{T}-\mathrm{C} 6^{\mathrm{c}}$ & $3.41^{\mathrm{d}}$ & $3.18^{\mathrm{d}}$ & $3.53^{\mathrm{d}}$ & $3.22^{\mathrm{d}}$ & $3.35^{\mathrm{d}}$ & $3.03^{\mathrm{d}}$ & 2.32 \\
\hline
\end{tabular}

${ }^{a}$ From reference 26 ; ${ }^{b}$ The values of $\mathrm{E}_{0}^{0}(100 \%)$ for molecules larger than 3T-C6 were obtained from a linear fitting procedure; ${ }^{\mathrm{c}} \mathrm{The}$ energy gap for the infinity polymer was calculated considering a linear behavior of $\mathrm{E}_{0}^{0}$ with $1 / \mathrm{n}$, being $\mathrm{n}$ the number of monomeric units; ${ }^{\mathrm{d}}$ This values were calculated without the 2T-C6 data. 
values for the 5T-C6 at both levels of theory. At the SVWN/ 6-31G(d)//HF/6-31G level, this result can be attributed to the less planar geometry calculated for the 6T-C6, however at the SVWN/6-31G(d)//HF/6-31G(d) level similar geometries were found for 5T-C6 and 6T-C6 structures (see Table 4). For the syn forms with HT-HT regioselectivity the energy gap variation was from 3.86 to $3.15 \mathrm{eV}$ and from 3.63 to $2.90 \mathrm{eV}$ respectively at both levels of theory considered.

The extrapolated energy gap to the infinity polymer was predicted. The DFT and ZINDO-S/CI results are reported on the Tables 5 and 6 respectively. The linear correlation was performed without considering the energy gap calculated for the 2T-C6 derivative, which do not presented polymeric characteristic. The quality of the correlation used to extrapolate the band gap from finite to infinite polymer is exemplified for the HT-HT derivatives in the syn and anti forms in Figure 3. Analyzing the DFT values in Table 5 it can be noted that the energy gap obtained for the anti form are quite similar for the HT-HT and HH-TT isomers, equal to 2.61 and $2.60 \mathrm{eV}$ (SVWN/6$31 \mathrm{G}(\mathrm{d}) / / \mathrm{HF} / 6-31 \mathrm{G})$ and 3.22 and $3.09 \mathrm{eV}(\mathrm{SVWN} / 6-$ $31 \mathrm{G}(\mathrm{d}) / / \mathrm{HF} / 6-31 \mathrm{G}(\mathrm{d}))$. For the HT-HT regioselectivity the syn form was also analyzed and the calculated energy gap found to be 2.54 and $2.79 \mathrm{eV}$ respectively at the both levels of theory mentioned before. The calculated values at SVWN/6-31G(d)//HF/6-31G are closer to the experimental, with the energy gap for the syn HT-HT differing only in $0.22 \mathrm{eV}$ from the observed value. According to our previous study ${ }^{10}$ the average deviation of calculated energy gap from the experimental data was $0.22 \mathrm{eV}$ at the SVWN//HF level that is in agreement with the result obtained in the present study $(0.29 \mathrm{eV}$ for the anti HT-HT and HH-TT and $0.22 \mathrm{eV}$ for the syn HT-HT

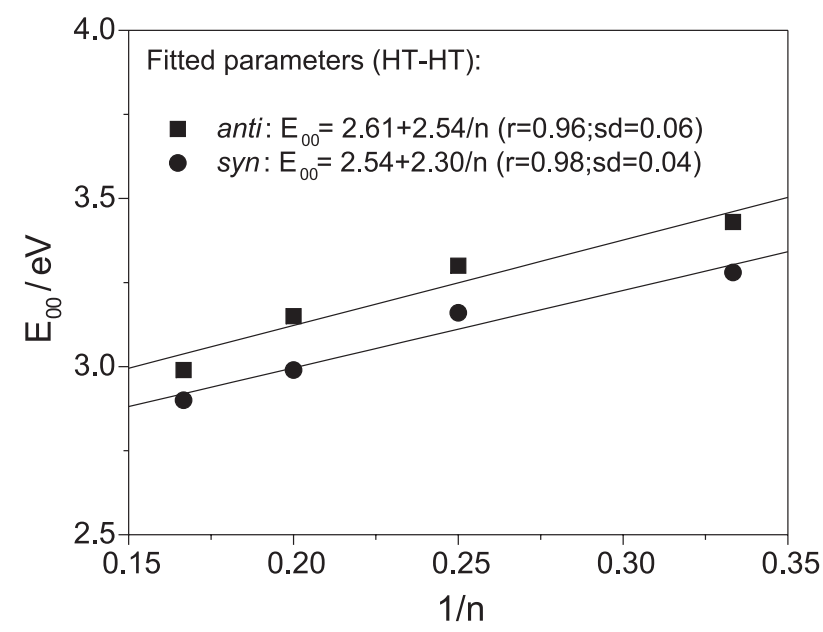

Figure 3. Correlation of energy gap $\left(\mathrm{E}_{0}^{0}\right)$ and the reciprocal of the number of thiophene units $(1 / \mathrm{n})$ for oligo(hexylthiophene). isomers). The ZINDO-S/CI values (Table 6) are higher than the DFT ones and are quite sensitive to the active space used in the $\mathrm{CI}$ procedure. In Table 6 all $\mathrm{E}_{0}^{0}$ values obtained considering only $10 \%$ of the valence molecular orbitals are reported in addition to the results considering all the valence molecular orbitals (VMO) calculated only for $2 \mathrm{~T}$ $\mathrm{C} 6$ and 3T-C6. For the longer oligomers the $\mathrm{E}_{0}^{0}$ considering $100 \%$ of VMO were calculated empirically considering a linear scaling developing in the present work.

Finally, the results obtained in the present study showed that the inclusion of alkyl side chain in thiophenes derivatives allows selective control of the molecular structure and microscopic energy gap that can be done with specific regioselectivities and is necessary but not sufficient to obtain the macroscopic properties.

\section{Conclusions}

The structure and energy gap were calculated for a series of alkylthiophenes using theoretical methodologies based on HF and DFT approaches. Two distinct regioselectivities in the anti and syn conformations were considered, defined according to the side chain position. For the alkylbithiophene (2T-R), the HT-HT isomers presented lower energy gap than the HH-TT derivatives. However for the longer oligo(alkylthiophenes) the gas phase calculated energy gap were found to be lower for the $\mathrm{HH}$ TT regioselectivity. The extrapolated energy gaps for the infinity polymer were 2.60 and $2.54 \mathrm{eV}$ respectively for the anti and syn HT-HT isomer at the SVWN/6-31G(d)// HF/6-31G level, which are in good accordance with the experimental value $(2.32 \mathrm{eV})$.

In general, our results show that the energy gap does not change significantly with the increasing of the side chain. This is important, once that more processable polymer can be obtained through alkylation with slight decreasing of energy gap that is an important molecular properties related to the electronic conductivity.

\section{Acknowledgments}

The authors would like to thank the Brazilian Agencies CNPq, FAPEMIG and FINEP for financial support and the CENAPAD-MG/CO-NAR/UFJF for computational facilities.

\section{References}

1. Shirakawa, H.; Louis, E. J.; Mac-Diarmid, A. G.; Chiang, C. K.; Heeger, G. A; J. Chem. Soc. Chem. Commun. 1977, 578. 
2. Scotheim, T., ed.; A.;Handbook of Conducting Polymers, Dekker, M.: New York, 1998; Nalwa, H. S.; ed.; Organic Conductive Molecules and Polymers, Wiley: Chichester, 1997; Brédas, J-L.; Silbey, R., eds.; Conjugated Polymers: The Novel Science and Technology of Highly Conducting and Nonlinear Optically Active Materials, Academic: Dordrecht, 1991; Brédas, J.-L.; Chance, R. R.; Conjugated Polymeric Materials: Opportunities in Electronics, Optoelectronics, and Molecular Electronics, Kluver Academic Publishers: London, 1989, p. 182.

3. Roncali, J.; Chem. Rev. 1992, 92, 71; Forrest, S. R.; Chem. Rev. 1997, 97, 1793.

4. Bäurle, P.; Thomas F.; Bidlingmeir, B.; Stabel A.; Rabe, J. P.; Angew. Chem. Int. Ed. Engl. 1995, 34, 303.

5. Prosa, T. J.; Winokur, M. J.; Moulton, J.; Smith, P.; Hegeer, A. J.; Phys. Rev. B 1995, 51, 4364.

6. Prosa, T. J.; Winokur, M. J.; Macromolecules 1996, 29, 3654.

7. McCullough, R. D.; Willians, S. P.; Tristram-Nagle, S.; Jayaraman, M., Ewbank, P. C.; Miller, L.; Synth. Met. 1995, 69, 279

8. McCullough, R. D.; Lowe; R. D.; Jayaraman, M.; Anderson D. L.; J. Org. Chem. 1993, 58, 904.

9. De Oliveira, M. A.; Duarte, H. A.; Pernaut, J-M.; De Almeida, W. B.; J. Phys. Chem. A 2000, 104, 8256.

10. De Oliveira, M. A.; Dos Santos, H. F.; De Almeida, W. B.; Int. J. Quantum Chem. 2002, 90, 603.

11. De Oliveira, M. A.; Dos Santos, H. F.; De Almeida, W. B.; Phys. Chem. Chem. Phys. 2000, 2, 3373.

12. Duarte, H. A.; Dos Santos, H. F.; Rocha, W. R.; De Almeida, W. B.; J. Chem. Phys. 2000, 113, 4206.

13. Ditchfield R.; Hehre, W. J.; Pople, J. A.; J. Chem. Phys. 1971 54, 724; Ditchfield, R.; Hehre, W. J.; Pople, J. A.; J. Chem. Phys. 1972, 56, 2257; Hariharan, P. C.; Pople, J. A.; Mol. Phys. 1974, 27, 209; Gordon, M. S.; Chem. Phys. Lett. 1980, 76, 163; Hariharan, P. C.; Pople, J. A.; Theor. Chim. Acta 1973, 28, 213.
14. Parr, R.G.; Yang, W.; Density Functional Theory of Atoms and Molecules, Oxford University Press: New York, 1989.

15. Slater, J. C.; Phys. Rev. 1951, 81, 385; Dirac, P.A.M.; Proc. Camb. Philos. Soc. 1930, 26, 376; Slater, J.C.; The Quantum Theory of Molecules and Solids, McGraw-Hill: New York, 1974, Vol. 4

16. Vosko, S. H.; Wilk, L.; Nusair, M.; Can. J. Phys. 1980, 58, 1200 .

17. Thompson, M. A.; Zerner M. C.; J. Am. Chem. Soc. 1991, 113, 8210; Thompson, M. A.; Glendening, E. D.; Feller D.; J. Phys. Chem. 1994, 98, 10465; Thompson, M. A.; Schenter, G. K.; J. Phys. Chem. 1995, 99, 6374; Thompson, M. A.; J. Phys. Chem. 1996, 100, 14492. INDO references: Ridley, J.; Zerner, M.; Theor. Chim. Acta 1973, 32, 111; Zerner, M. C.; Loew, G. H., Kirchner, R. F.; Mueller-Westerhoff, U. T., J. Am. Chem. Soc. 1980, 102, 589; Zerner, M. C. In Reviews in Computational Chemistry II; Libkowitz, K. B.; Boyd, D. B., eds.;VCS Publishers Inc.: New York, 1991, Chapter. 8 p. 313

18. Hutchison,G.R.; Ratner,M.A.; Marks,T.J.; J. Phys. Chem. A 2002, 106, 10596.

19. Koopmans, T.; Physica 1934, 1, 104.

20. Levy, M. ; Nagy, A.; Phys. Rev. A 1999, 59, 1687.

21. Janak, J. F.; Phys. Rev. B, 1978, 18, 7165.

22. Samdal, S.; Samuelsen, E. J.; Volden, H. V; Synth. Met. 1993, $59,259$.

23. Bongini, A.; Bottoni,A.; J. Phys. Chem. A 1999, 103, 6800.

24. dos Santos,D.A.; Galvão, D. S.; Laks, B.; dos Santos, M. C.; Chem. Phys. Lett. 1991, 184 579; dos Santos, D. A.; Galvão, D. S.; Laks, B.; dos Santos, M. C.; Synth. Met. 1992, 51, 203.

25. Garcia, P.; Pernaut, J.-M.; Hapiot, P.; Wintgens, V.; Valat, P.; Garnier, F.; Delabouglise, D.; J. Phys. Chem. 1993, 97, 513.

26. Pernaut, J.-M., unpublished results.

Received: March 4, 2004 Published on the web: October 7, 2004 